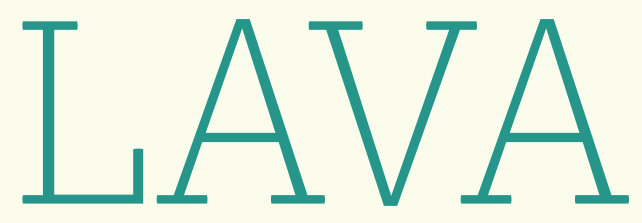

Matéria liquida lançada pelos vulcões.

Torrente, enxurrada, curso. 



\title{
FERVOR E
}

MELANCOLIA:

A EXPERIÊNCIA URBANA

EM JORGE LUIS BORGES

\author{
- PATRÍCIA LEME
}

\section{RESUMO}

Este trabalho propõe uma interpretação da experiência urbana em Fervor de Buenos Aires, primeiro livro de Jorge Luis Borges, a ser modulada pela poética de Charles Baudelaire. A relação será estabelecida por meio da temporalidade mobilizada nos poemas eleitos, aspecto poético que constitui configurações espaciais específicas: enquanto a Paris de Baudelaire não se fixa, a Buenos Aires borgeana permanece congelada no tempo, diferença que coloca em questão as abordagens poéticas do tema da cidade na modernidade literária.

Palavras-chave: Jorge Luis Borges, Charles Baudelaire, experiência urbana, temporalidade, modernidade literária.

\section{ABSTRACT}

This work proposes an interpretation of urban experience in Jorge Luis Borges' first book, Fervor de Buenos Aires, to be modulated by Charles Baudelaire's poetic oeuvre. This relation will be established through temporality as mobilized in the selected poems, a poetic aspect that creates specifics spatial configurations: whereas Baudelaire's Paris doesn't stop, the borgesian Buenos Aires stays frozen in time, difference that calls into question the many poetic approaches to the theme of the city during the literary modernity.

Key-words: Jorge Luis Borges, Charles Baudelaire, urban experience, temporality, literary modernity.

Visito os fatos, não te encontro.

Onde te ocultas, precária síntese, penhor de meu sono, luz dormindo acesa na varanda?

(Carlos Drummond de Andrade) 


\title{
I. INTRODUÇÃO: A EXPERIÊNCIA URBANA EM DOIS TEMPOS
}

\author{
$A^{\text {l otro, a Borges, es a quien le ocurren las cosas. Yo camino por }}$ \\ 1 Buenos Aires y me demoro, acaso ya mecánicamente, para mirar \\ el arco de un zaguán y la puerta cancel; de Borges tengo noticias por el \\ correo y veo su nombre en una terna de profesores o en un diccionario \\ biográfico. (...) Sería exagerado afirmar que nuestra relación es hostil; \\ yo vivo, yo me dejo vivir, para que Borges pueda tramar su literatura $y$ \\ esa literatura me justifica (BoRgES, 1997, p. 351)1 .
}

Assim Jorge Luis Borges inicia "Borges y yo", célebre texto publicado originalmente em 1960, em El hacedor. Nesse poderoso conto, composto em um parágrafo de poucas linhas, o escritor traz à cena seu hábito de caminhar pela cidade. A utilização do tempo presente acentua a familiaridade do percurso, e, inscrevendo-o como um empuxo (agora automático) à errância pelas ruas de Buenos Aires, mobiliza também a sutil rede de afetos emanada por tal costume; assim fazendo, a instância organizadora do relato delineia uma importante polaridade no fazer literário do autor: enquanto o eu que enuncia caminha só pela cidade, deixando-se viver, um outro chamado Borges engendra a obra que marcará o cânone ocidental. Na passagem entre um e outro, do eu que narra ao grande nome que produzirá o conto já em processo, está a clivagem que orienta esta proposta de leitura: a produção borgeana marca-se por uma espécie de síntese entre a experiência perdida e a potência criadora, agenciando uma estratégia ímpar no que tange às relações possíveis entre escrita e elaboração subjetiva.

Na obra de Borges, alguns elementos se estabelecem como suportes dessa tensão; tratando das mitologias do arrabalde ou dos jogos com o tempo e com o infinito (cf. Borges, 1997, p. 351), Borges com frequência lançará mão do tempo presente para dar forma a duas forças coexistentes, dois momentos feitos convergir por um poderoso ato enunciativo

[1] "Ao outro, a Borges, é que sucedem as coisas. Eu caminho por Buenos Aires e me demoro, talvez já mecanicamente, para olhar o arco de um vestíbulo e o portão gradeado; de Borges tenho notícias pelo correio e vejo seu nome numa lista tríplice de professores ou num dicionário biográfico. (...) Seria exagerado afirmar que nossa relação é hostil; eu vivo, eu me deixo viver, para que Borges possa tramar sua literatura, e essa literatura me justifica" (Borges, 2008, p. 54). 
(cf. PigliA, 2004, p. 101). ${ }^{2}$ Dentre as figurações dessa tensão constitutiva da escrita borgeana, Buenos Aires, cidade natal do escritor, emerge com recorrência que não pode ser ignorada, estabelecendo um tópos que impele esta leitura a retornar ao seu primeiro gesto de escrita. Nesse sentido, Fervor de Buenos Aires, obra poética publicada em 1923, será tomado como momento de fundação de uma proposta literária: o livro alça-se ao estatuto de precursor dos problemas que a obra de Borges, posteriormente consagrada pelo manejo com a temporalidade cíclica e os espaços labirínticos, colocará à literatura ocidental. A primeira experiência literária, uma singela homenagem à cidade aberta ao sujeito poético, esboça a poderosa enunciação que, pelas mãos de um Borges tardio - ou, por que não, crepuscular -, redefinirá as relações entre a literatura e a realidade, leitura e tradição, escrita e memória.

À hipótese de fazermos desse marco inaugural uma espécie de mito de fundação de sua obra o próprio escritor responde, em um prefácio de 1969 à versão presente nas Obras Completas, com uma inquietante consideração:

(...) he sentido que aquel muchacho que en 1923 lo escribió ya era esencialmente - ¿qué significa esencialmente? - el señor que ahora se resigna o corrige. Somos el mismo (...). Para mí, Fervor de Buenos Aires prefigura todo lo que haría después (Borges, 1994, p.13) ${ }^{3}$.

Por mais de uma via, a cidade é cantada em dois tempos: no território encerrado por Fervor de Buenos Aires, o jovem que timidamente escrevera porta o grande escritor por vir. Se tomada à luz das palavras do futuro senhor, a relação com o espaço urbano nesses poemas bem como as opções estéticas que produzem tal figuração dão indícios de que o próprio livro já se institui por meio de uma complexa dinâmica temporal - ainda que suas tensões, na hipótese a ser investigada, permaneçam em latência. Borges opta por manter intacta uma Buenos Aires de casas baixas e de chácaras cercadas (p. 13), aquela à qual supõe ter

[2] Saliento que a dimensão aberta pela utilização do tempo presente na escrita borgeana compõe um aspecto importante de minha pesquisa de doutorado, em andamento desde 2014 e realizada sob orientação da Profa. Dra. Cleusa Rios Pinheiro Passos no Depto. de Teoria Literária e Literatura Comparada (FFLCH-USP).

[3] “(...) senti que aquele rapaz que em 1923 o escreveu já era essencialmente - que significa essencialmente? - o senhor que agora se resigna ou corrige. Somos o mesmo (...). Para mim, Fervor de Buenos Aires prefigura tudo o que faria depois (BorgEs, 2000, p. 11). 
outrora conhecido ${ }^{4}$; esse ato, em oposição ao título - predicado por um suposto "fervor" -, agrega-lhe uma melancolia não pronunciada. Aqui está o indício de que, na metrópole estática de Fervor de Buenos Aires, há também dois tempos em operação.

Se por um lado Fervor de Buenos Aires inaugura a obra borgeana, então atenta à capital argentina, aos mitos e escritores nacionais, por outro o livro inscreve-se de imediato em um escopo mais amplo: aquele que, na tradição literária ocidental, dedica-se a um olhar à cidade e à problematização da experiência urbana. Por essa via, a obra de Charles Baudelaire faz-se uma referência inescapável para a abordagem da Buenos Aires borgeana: pois a Paris baudelairiana é uma cidade que muda e, ao fazê-lo, obriga o sujeito poético a assumir uma posição irremediavelmente afetada por tal instabilidade. Nesta leitura, a cidade de Baudelaire definirá, então, um étimo à experiência urbana em Fervor de Buenos Aires, de modo que possibilite precisar, por meio da referência ao marco moderno, a curvatura produzida pela proposta de Borges. Para além da oposição, este exercício interpretativo visa, por meio de um adensamento de contrastes, revelar uma imagem latente na perene urbe de Borges: aquela que traz, com seu fervor inaudito, traços da voz solitária que rasga as multidões nas grandes cidades.

\section{II. "PARIS CHANGE": SPLEEN NA CIDADE QUE FERVILHA}

A poética de Baudelaire é atravessada pela exímia manutenção do contraste - e talvez por isso Borges o tenha considerado "um homem de mau gosto" (APUD JOZEF, 1999, p.30)5. A apreciação do escritor argentino, autoral inclusive na eleição de seu cânone particular, parece ir simultaneamente de e ao encontro do que postula a vasta crítica de Baudelaire: firmemente opondo-se à opção estética do poeta da modernidade, o comentário de Borges acaba por tangenciar uma de suas características mais instigantes, à

[4] Como sustenta Antonio Cajero: "El Buenos Aires de Borges, entonces, resulta en buena medida de la reconstrucción de los restos de una ciudad que le llega mediante las crónicas familiares, los recuerdos infantiles, las lecturas de Carriego y Eduardo Gutiérrez: una idea de la ciudad que opone a la ciudad concreta". "“A Buenos Aires de Borges, então, resulta em boa medida da reconstrução dos restos de uma cidade que lhe chega mediante as crônicas familiares, as recordações infantis, as leituras de Carriego e Eduardo Gutiérrez: uma ideia da cidade que se opõe à cidade concreta"] (CAJERO, 2006, p. 112). As traduções dos textos críticos presentes neste artigo são de minha autoria.

[5] Assim Bella Jozef encadeia as voluntariosas opiniões de Borges acerca do cânone literário francês: "Da literatura francesa, escapam poucos: Verlaine e Hugo. Baudelaire 'é um homem de mau gosto', Valéry 'tem a mais absurda metáfora da poesia contemporânea, comparou o mar a um telhado', Mallarmé 'foi obcecado pela inovação', a literatura de Proust 'repousa no mexerico'” (1999, p. 30). 
qual se atenta, por exemplo, Eric Auerbach. Para o teórico, o escândalo que a literatura de Baudelaire gerou se estabelece no âmago de uma ruptura:

(...) [Em Baudelaire há uma] contradição entre o tom elevado e a indignidade tanto do tema como um todo quanto de seus muitos detalhes. Este contraste perturbou muitos de seus contemporâneos como uma ruptura de estilo; foi violentamente atacado na época (...) (Auerbach, 2007, p. 309) 6 .

Tal consideração é atravessada pela leitura do poema "Spleen", presente no seminal Les Fleurs du mal; nesse texto, é precisamente a dissonância entre a dicção elevada e as imagens rebaixadas que produz a mola mestra do efeito poético. Composto por cinco quartetos, nele o sujeito poético empenha-se em criar uma atmosfera perturbadora, indiciada desde a primeira estrofe:

Quand le ciel bas et lourd pèse comme un couvercle Sur l'esprit gémissant en proie aux longs ennuis, Et que de l'horizon embrassant tout le cercle Il nous verse un jour noir plus triste que les nuits;

(...)

(BAUDELAIRE, 2006, p. 274, v. 1-4)7.

O poema tem início com uma oração temporal, deixando em suspenso a ação a que tal realização está apensa; a estrutura se repetirá no segundo e no terceiro quarteto, prolongando a expectativa:

(...)

Quand la terre est changée en un cachot humide,

Où l'Espérance, comme une chauve-souris,

S'en va battant les murs de son aile timide

Et se cognant la tête à des plafonds pourris;

[6] Em consonância com Paul Valéry, outro poeta "renegado" por Borges: "Nos melhores versos de Baudelaire há uma combinação de carne e de espírito, uma mistura de solenidade, de calor e de amargura, de eternidade e de intimidade, uma aliança raríssima da vontade com a harmonia que os distinguem nitidamente dos versos românticos, como distinguem nitidamente dos versos parnasianos" (VALÉRY, 2011, p. 27).

[7] "Quando o céu plúmbeo e baixo pesa como uma tampa / Sobre o espírito exposto aos tédios e aos açoites, / E, ungindo toda a curva do horizonte, estampa / Um dia mais escuro e triste do que as noites” (BAUDELAIRE, 2006, p. 275). 


\author{
Quand la pluie étalant ses immenses traînées \\ D'une vaste prison imite les barreaux, \\ Et qu'un peuple muet d'infâmes araignées \\ Vient tendre ses filets au fond de nos cerveaux, \\ (...) \\ (p. 274, v. 5-12)
}

Orientados pela conjunção "quando", os versos parecem aguardar um acontecimento em torno do qual se cria um crescendo de imagens (cf. AuerBACH, 2007, p. 305): algo ocorre quando o céu baixa como uma tampa, quando a terra se muda em um calabouço úmido (v. 5), quando a chuva simula as barras de uma grande prisão (v. 9-10). O início de cada estrofe cria o emparelhamento sintático no qual "céu", "terra" e "chuva" formam o ciclo inescapável da tempestade por vir - o céu avoluma-se e escurece o espírito entediado; a terra, seu oposto natural, aprisiona a Esperança tal qual um morcego que, desesperado, debate-se sem encontrar saída; a chuva, por fim, encerra o sujeito poético em uma poderosa arquitetura temporal.

Sincrônicas em sua sintaxe, as três versões desse dia escuro encadeiam-se e, passo a passo, configuram um efeito de processo: a tempestade que se arma está em plena moção quando irrompe - científico, preciso, demasiadamente real - o significante "cérebro" em meio às metáforas naturais ( "Et qu'un peuple muet d'infâmes araignées / Vient tendre ses filets au fond de nos cerveux, "[v. 11-12]); destoante, a palavra marca o tom desencontrado da tessitura do poema, compondo na desarmonia com a tradição um solavanco na leitura. Essa disposição cria a atmosfera na qual se ergue, através de um discurso direto, a voz do sujeito poético na última estrofe:

\title{
(...)
}

- Et de longs corbillards, sans tambours ni musique,

Défilent lentement dans mon âme; l'Espoir,

Vaincu, pleure, et l'Angoisse atroce, despotique,

[8] “(...) / Quando a terra se torna um calabouço horrendo, / Onde a Esperança, qual morcego espavorido, / Sua asa tímida nos muros vai batendo / E a cabeça roçando o teto apodrecido; // Quando a chuva, a escorrer as tranças fugidias, / Imita as grades de uma lúgubre cadeia, / E a muda multidão das aranhas sombrias / Estende em nosso cérebro uma espessa teia, / (...)" (IBIDEM). 
Sur mun crâne incliné plante son drapeau noir.

(p. 274, v. 17-20) ${ }^{9}$.

Nessa bizarra marcha "sans tambours ni musique", enquanto chora a Esperança a Angústia crava-lhe no crânio uma bandeira negra; o desfile, por fim, fecha-se com o mesmo "noir" que descendia sobre aquele dia já na primeira estrofe (v. 4). É nesse universo povoado, mutável e, por que não, violento que o sujeito poético se rende ao humor negro do spleen. Esse é o terreno do qual, poucas páginas adiante, brotarão os Tableaux parisiens de Baudelaire.

A segunda seção de Les Fleurs du mal, sequente a Spleen et idéal, dedica-se a sobrepor pequenos quadros da vida parisiense - e, com isso, a compor um todo mais verossímil ao espírito do flâneur do que a uma montagem referencial da cidade. O modo pelo qual Paris se estabelece parece obedecer a uma espécie de captação que, como postula Walter Benjamin, deriva de um "álbum de gravuras coloridas" a forma de um "imenso gravador": uma multidão sem face nem história (cf. BENJAMIN, 1989, p.46), um acúmulo de imagens tão poderoso que só poderia ressoar, em constante movimento, as efêmeras impressões de um jovem poeta errabundo. Nessa deriva, funda-se o conceito de modernidade literária:

Baudelaire meditou sobre o conceito da modernidade numa extensão bem diversa dos românticos. É um conceito muito complexo. Sob o aspecto negativo, significa o mundo das metrópoles sem plantas com sua fealdade, seu asfalto, sua iluminação artificial, suas gargantas de pedra, suas culpas e solidões no bulício dos homens. (...) Mas o conceito de modernidade de Baudelaire tem ainda outro aspecto. É dissonante, faz do negativo, ao mesmo tempo, algo fascinador (FRIEDRICH, 1978, p. 43).

Pela perspectiva de Eric Friedrich, Baudelaire, um "homem de mau gosto" (BORGES APUD JOZEF, p. 30), irá dedicar-se a compor uma modernidade cujo brilho nasce do baixo, outrora indigno de se tornar matéria poética. Em seus escritos pululam as velhas, os mendigos, as prostitutas, os sons das fábricas, negras emagrecidas pela crueza urbana. Extrair disso qualquer espécie de fascínio exige, para dizer o mínimo, uma delicadeza ímpar no trato poético: para que a realidade não esmague a poesia, o olhar do

[9] “(...) / - Sem música ou tambor, desfila lentamente / Em minha alma uma esguia e fúnebre carreta; / Chora a Esperança, e a Angústia, atroz e prepotente, / Enterra-me no crânio uma bandeira preta” (IBIDEM). 
sujeito poético deve ser rápido, instantâneo, aberto ao efêmero que, quiçá, pelo ângulo adequado e sob precisa iluminação, será digno da eternidade.

A necessidade de incorporar essa rápida dinâmica ao fazer poético produz uma escrita definida pelos encontros fortuitos. Tal condição, ao mesmo tempo em que coloca o sujeito enunciador em meio ao heterogêneo, porém massificado, turbilhão urbano, reafirma a sua impossível apreensão. Um dos momentos mais efetivos dessa espécie de moldura ao acaso seria, certamente, o consagrado "À une passante" (BAUDELAIRE, 2006 p. 318-320), soneto da "dor majestosa" que atravessa o sujeito poético para nunca retornar:

La rue assourdissante autour de moi hurlait.

Longue, mince, en grand deuil, douleur majestouse

Une femme passa, d'une main fasteuse

Soulevant, balançant le feston et 'lourlet;

Agile et noble, avec sa jambe de statue.

Moi, je buvais, crispé comme un extravagant,

Dans son oeil, ciel livide où germe l'ouragtan,

La douceur qui fascine et le plaisir qui tue.

(...)

(BAudeLAire, 2006, p. 318, v.1-8) ${ }^{10}$.

Da rua rumorosa surge, nos quartetos iniciais, a visão dessa mulher - bela, esguia, vestida de luto; ela, colocando o instante em eterno movimento, jamais se fixa. Essa figura, fazendo-se mãos, pernas, olhar, vestido, porta "La douceur qui fascine et le plaisir qui tue" (v.8); mas tão logo surge, arrebatando o sujeito poético, tão logo se imiscui na massa informe da cidade, nos dois tercetos que arrematam o poema:

(...)

Un éclair... puis nuit! - Fugitive beauté

Dont le regard m'a fait soudainnement renaitre,

Ne te verrai-je plus que dans l'éternité?

[10] "A rua em torno era um frenético alarido. / Toda de luto, alta e sutil, dor majestosa, / Uma mulher passou, com sua mão suntuosa / Erguendo e sacudindo a barra do vestido. // Pernas de estátua, era-lhe a imagem nobre e fina. / Qual bizarro basbaque, afoito eu lhe bebia / No olhar, céu lívido onde aflora a ventania, / A doçura que envolve e o prazer que assassina. / (...)” (BaUdelalRE, 2006, p. 319). 
Ailleurs, bien loin d'ici! trop tard! jamais peut-être!

Car j'ignore oú tu fuis, tu ne sais oú je vais,

O toi que j'eusse aimée, ô toi qui le savais!

(p. 320, v. 9-14) 11.

De um relâmpago, imagem produtora de uma luz total, rompe a noite; a mulher vem e passa, apagando-se na multidão. Para sempre clandestina, essa passante dá corpo ao impossível da experiência - a isso que, repentino, não se detém. Benjamin se atentará para essa dimensão ao aludir para a potência traumática do choque: trata-se de um acontecimento não incorporável à consciência, da qual o psiquismo não consegue se proteger (cf. BENJAMIN, 1989, p. 108-113); falhando em absorver o ocorrido, o sujeito permanece sem "traduzi-lo" a um registro acessível e por isso não o retém, permanecendo às escuras no que tange aos inescapáveis efeitos da passagem. A experiência traumática insiste como um rastro indelével, mas radicalmente não-sabido, a ser reencontrado apenas quando o ato interpretativo mobiliza, por meio do vazio deixado, aquilo que não possui inscrição em primeiro lugar. O trauma precisa, portanto, de dois tempos, duas cenas - a elaboração futura inscreverá retroativamente a cena a ser interpretada como traumática ${ }^{12}$.

Nessa indistinção de registros, entre as potencialidades poéticas da experiência e a sua incorporação estéril ao acervo consciente das vivências (cf. BENJAmin, 1989, p.110), reside o gesto de criação; como propõe Flavia Trocoli:

[Benjamin] dá a ver a feição eminentemente antinaturalista da poesia baudelairiana, a massa anônima e ruidosa jamais é descrita, mas sim evocada, flagrada em seus efeitos. Em A uma passante, na massa estão dissolvidos sujeito e objeto, sem olhar, sem voz. Como Albertine, inicialmente, está em estado de anonimato, encoberta ou $\grave{A}$ sombra das raparigas em flor. Contudo, eles - o amante, a amada, o olhar e a

[11] “(...) / Que luz... e a noite após! - Efêmera beldade / Cujos olhos me fazem nascer outra vez, / Não mais hei de te ver senão na eternidade? // Longe daqui! tarde demais! nunca talvez! / Pois de ti já me fui, de mim tu já fugiste, / Tu que eu teria amado, ó tu que bem o viste!" (BAudelaire, 2006, p. 321).

[12] Para traçar tal percurso, Benjamin lança mão de "Além do princípio de prazer" (1920[1989]), um dos mais importantes textos de Sigmund Freud, divisor de águas na teoria psicanalítica que continua gerando importantes desdobramentos teóricos. Para os fins deste trabalho, este viés não será aprofundado, mas saliento que o comentário acima foi produzido também à luz de "Nota sobre o 'bloco mágico'” (FREUD, 1925[1992]) e "Lituraterra" (LACAN, 2003). Sobre a dimensão das duas cenas que compõem o trauma -operação de rasura, pela via de Jacques Lacan -, sugiro a leitura de Flavia Trocoli (2012) sobre a obra proustiana. 
voz, a serem singularizados - estão na massa indistinta contidos em potência, à espera do acaso e do ato poético (TROcoli, 2012, p. 205).

É dessa amálgama que o sujeito poético se desenlaça, e, "Do ruído ao canto" (TROCOLI, 2012, p. 207), imprime lirismo sobre o jamais do reencontro - dois tempos condensados no gesto de criação. O acontecimento da passante é da ordem de um clarão que, ao sujeito poético, só poderá se traduzir em noite: ele se desembaraça da multidão para ser aquele que perde, e para dessa matéria abjeta fazer sua poesia ${ }^{13}$. Ser o "objeto dos encontrões da multidão" (BENJAmin, 1989, p. 144): esse é o projeto ao qual Baudelaire, por mais que com ele se debata, por mais que chegue a renegá-lo, realiza, com todos os seus contrastes e ambivalências ${ }^{14}$.

Em Le fleurs du mal, após o doce deleite almejado em "Paysage", o poeta-esgrimista de "Le soleil", que abre a multidão com gestos certeiros, esquiva-se da bela mendiga ruiva para, no quarto poema, melancolicamente postular: "Paris change!" (BAUdELAIRE, 2006, p.303, v.29)15 . "Le cygne", poema rompido em duas partes, retrata com sublime acuidade os dois tempos que compõem a cena poética: se o animal, imagem arrebatadora que emerge na quinta estrofe, clama aos céus "Eau, quand donc pleuvras-tu? quand tonneras-tu foudre?" (v. 23) ${ }^{16}$, ecoa, em resposta, o "trop tard! jamais peut-être!" de "À une passante". O tempo da experiência, ansiado pela poesia que se agita, só se estabelece quando já perdido.

[13] Trago en passant (e com irresistível trocadilho) mais um trecho da breve análise de Flavia Trocoli, lendo Baudelaire retroativamente com Proust: "O eu lírico dá voz primeiramente à rua, ao seu frenético alarido, de onde se recortará a figura da passante. (...) No entanto, da amada não se faz um retrato, o funcionamento passa a ser metonímico: mão, perna, olhar, tal como o vestido reduz-se à sua barra. O narrador de A prisioneira e de A fugitiva também esbarrará na impossibilidade de totalizar a imagem de Albertine. Beber no olhar da passante crispa o poema de oxímoros (...), no cruzamento, o eu lírico também ganha forma, renasce. Do ruído ao canto. Tão subitamente quanto não a verá mais, talvez na eternidade? Alhures, tarde demais, o corvo de Poe - nevermore - é traduzido e citado em itálico: jamais. O cruzamento se desfaz, a passante desapareceu (...)" (Trocol, 2012, p. 206-207).

[14] Segundo Benjamin: "O autor desses escritos não é um flâneur. (...) Para [Baudelaire] havia se apagado a ilusão de uma multidão com impulsos próprios, com alma própria, porque o flâneur havia se deslumbrado. Para imprimir em si sua vileza, ele não perde de vista o dia em que até mesmo as mulheres perdidas, as rejeitadas, chegarão ao ponto de ditar preceitos à vida regrada, de condenar a libertinagem e não deixar subsistir nada além do dinheiro. Traído por esses seus últimos aliados, Baudelaire se volta contra a multidão; e o faz com a fúria impotente de quem luta contra a chuva e o vento. Tal é a natureza da vivência que Baudelaire pretendeu elevar à categoria de verdadeira experiência. Ele determinou o preço que é preciso pagar para adquirir a sensação do moderno: a desintegração da aura na vivência do choque" (Benjamin, 1989, p. 144-145).

[15] “Paris mudou!" (BAUdelaiRe, 2006, p. 302).

[16] “Água, não choverás? Não trovejarás, raio?” (IBIDEM). 


\section{ESTÉTICA ESTÁTICA: A MELANCOLIA DE BUENOS AIRES}

Diante das poderosas imagens que o gênio baudelairiano levanta, cabe uma questão: como uma construção tão poderosa não se fixa, sendo insustentável senão enquanto dura o poema? A mulher que passa, o cisne que se desembaraça de sua gaiola, a bandeira negra que recobre o sujeito poético - metáforas potentes, mas caducas, sacrificadas à moção da cidade e à passagem do tempo. Não à toa Jean Starobinski aliará o cúmulo da melancolia posto em cena por Baudelaire à invocação alegórica: “(...) um meio de conjurar a passagem do tempo e as imagens da destruição, certamente, mas ao custo de paralisar toda a vida (...)" (STAROBINSKI, 2014, p. 69). Baudelaire sucede em articular congelamento e transitoriedade, em fazer surgir do estático uma irreparável fluidez - um ruidoso gravador emana de um colorido álbum de fotografias e, em pleno processo, nos faz ouvir aquilo que a imagem não aprisiona (cf. BENJAMin, 1989, p. 46). Ao trazer no que era imóvel pura mutação, fenômeno contemporâneo, de lapso ou captação ${ }^{17}$, a poética de Baudelaire não recria a cidade real, mas, sim, cria os efeitos reais de uma Paris agora moderna. Nela, o sol ora atormenta a cidade com sua luz direta, como em "La belle Dorothée" (BAUdelAire, 2006, p. 140), ora seus raios outonais parecem demorar-se no céu já esverdeado, como "Les vocations" (BAUDELAIRE, 2006, p.190) ${ }^{18}$, sem que jamais se estabeleça em uma impressão durável. Para que a realidade não recubra seus relances poéticos, as poderosas imagens levantadas não devem se estabilizar, deixando o leitor também aos encontrões.

A passagem por Baudelaire permitiu identificar um aspecto central de sua poética: contando com imagens potentes, mas fugazes, com os oxímoros e dissonâncias pelas quais elas se produzem, com a sensação de contraste absoluto que isso gera, o modus operandi do poeta parece ter seu eixo na explosão das tensões de sua época. Edificada sob esse complexo signo, a urbe baudelairiana, como dirá Karl Stierle, queda submetida a uma temporalidade muito particular, “(...) soumise à la loi de

[17] Como traz Giorgio Agamben, em "O que é o contemporâneo?": "O poeta - o contemporâneo - deve manter fixo o olhar no seu tempo. Mas o que vê quem vê o seu tempo, o sorriso demente do seu século? Neste ponto gostaria de lhes propor uma segunda definição da contemporaneidade: contemporâneo é aquele que mantém fixo o olhar no seu tempo, para nele perceber não as luzes, mas o escuro" (AgAmben, 2009, p. 62); e, posteriormente, "Por isso os contemporâneos são tão raros. E por isso ser contemporâneo é, antes de tudo, uma questão de coragem: porque significa ser capaz não apenas de manter fixo o olhar no escuro de sua época, mas também de perceber nesse escuro uma luz que, dirigida para nós, distancia-se infinitamente de nós. Ou ainda: ser pontual num compromisso ao qual se pode apenas faltar" (AgAmBEn, 2009, p. 65).

[18] Ambos os textos integram os Pequenos poemas em prosa (BAUdelaire, 2006). 
la discontinuité des moments du temps qui, chacun en soi, sont chargés à l'extrême d'actualité" (STIERLE, 2001, p.475) ${ }^{19}$. A proposta borgeana parece trilhar o caminho oposto: ao contrário de alguns de seus contemporâneos, Borges prefere compor as casas e bairros de Fervor de Buenos Aires por meio de "(...) su imagen del pasado, estática en el tiempo y intocada por la modernidad" (CAJERO, 2006, p. 110) ${ }^{20}$. Há, contudo, uma singularidade nessa emblemática nostalgia: para reconstruir aquilo que está desaparecendo, o poeta lança mão da tradição literária e da memória de terceiros (cf. SARLo, 2008, p. 50), criando uma imagem de Buenos Aires que, irreal e perene, irrompe frente à cidade em transição ${ }^{21}$. Trata-se de uma nostalgia sem objeto concreto, ou de uma ausência sem um referencial específico, e por isso mesmo se sustenta enquanto tal ${ }^{22}$.

O processo poético de Fervor de Buenos Aires atém-se a uma espécie de imobilização do espaço pelo tempo: a iluminação da tarde, elemento temporal, parece recobrir os espaços pelos quais o sujeito poético transita. "Calle desconocida", quarto poema do livro, nos oferece com belíssima moldura a dimensão desse espaço tocado pelo crepúsculo:

\author{
Penumbra de la paloma \\ llamaron los hebreos a la iniciación de la tarde \\ cuando la sombra no entorpece los pasos \\ y la venida de la noche se advierte \\ como una música esperada y antigua, \\ como un grato declive. \\ En esa hora en que la luz \\ tiene una finura de arena, \\ di con una calle ignorada,
}

[19] “(...) submissa à lei da descontinuidade de momentos do tempo que são, cada um em si, carregados de extrema atualidade".

[20] "(...) sua imagem do passado, estática no tempo e intocada pela modernidade".

[21] Como nota Beatriz Sarlo: "Só se pode sentir nostalgia por alguma coisa que se perdeu. Numa Buenos Aires transformada pelos processos de modernização urbana, em que a cidade criolla se refugiava numas poucas ruas de bairro, que por sua vez também se transformavam em seu papel físico e demográfico, Borges inventou um passado. (...) Mas mesmo esses fragmentos e as imagens de seus ancestrais criollos eram ameaçados pelo tempo, pela modernidade e pelo esquecimento" (SARLo, 2008, p. 69).

[22] Como traz Agamben a respeito da melancolia: "Freud não esconde o seu embaraço diante da irrefutável constatação de que, enquanto o luto sucede a uma perda realmente acontecida, na melancolia não só falta clareza a respeito do que foi perdido, mas nem sequer sabemos se podemos de fato falar de uma perda. 'Deve-se admitir' - escreve ele com certo desapontamento - 'que se produziu uma perda, mas sem que se consiga saber o que foi perdido'. Além disso, procurando suavizar as contradições a partir das quais haveria uma perda, mas não um objeto perdido, ele fala logo depois de uma 'perda desconhecida', ou de uma 'perda objetual que escapa à consciência'." (2007, p.44) 
abierta en noble anchura de terraza,

cuyas cornisas y paredes mostraban

colores blandos como el mismo cielo

que conmovía el fondo.

Todo - la medianía de las casas,

las modestas balaustradas y llamadores,

tal vez una esperanza de niña en los balcones -

entró en mi vano corazón

con limpidez de lágrima.

Quizá esa hora de la tarde de plata

diera su ternura a la calle,

haciéndola tan real como un verso

olvidado y recuperado.

Sólo después reflexioné

que aquella calle de la tarde era ajena,

que toda casa es un candelabro

donde las vidas de los hombres arden

como velas aisladas,

que todo inmediato paso nuestro

camina sobre Gólgotas.

(Borges, 1994, p. 20) ${ }^{23}$.

O poema é inicialmente marcado pela penumbra iniciada com a $\operatorname{tarde}^{24}$. A vinda da noite, que logo mais recobrirá a rua desconhecida, ainda não se deu: o sujeito poético encontra-se em um espaço sem nome, no limite último de um tempo quando "la luz tiene una finura de arena" (v. 7-8). A imagem estabelece uma fragilidade, revelando no poema o caráter efêmero de sua própria constituição: os grãos de areia compõem o fio de um tempo a escorrer diante de nossos olhos, mas que, contudo, é

[23] "De penumbra da pomba / chamaram os hebreus a iniciação da tarde, / quando a sombra não entorpece os passos / e o anoitecer é percebido / como uma música esperada e antiga, / como um grato declive. / Nessa hora em que a luz / tem a finura da areia, / dei com uma rua ignorada, / nobre em sua largura de terraço, / cujas cornijas e paredes mostravam / cores suaves como o próprio céu / que comovia o fundo. / Tudo - a mediania das casas, / as modestas balaustradas e aldravas, / talvez uma esperança de menina nas sacadas - / entrou em meu inútil coração / com limpidez de lágrima. / Talvez essa hora da tarde prateada / concedesse à rua sua ternura, / tornando-a a tão real quanto um verso / esquecido e resgatado. / Só depois ponderei / que aquela rua ignorava a tarde, / que toda casa é um candelabro / onde as vidas dos homens ardem / como velas isoladas, / que todo impensado passo nosso / caminha sobre Gólgotas" (BoRGEs, 2007, p. 25-27).

[24] Cabe lembrar que, na tradição judaica, os dias se contam de tarde a tarde, e não de manhã a manhã; conforme esclarece o personagem Red Scharlach, antagonista de "La muerte y la brújula”: "(...) ese pasaje manifiesta que los hebreos computaban el día de ocaso a ocaso (...)" (Borges, 1996, p.16). 
eternizado pela contemplação poética. O entardecer, prenhe de mistérios e de mudança, oferece uma figuração estática de uma cidade "tan real como un verso" (v. 21) - aqui, o tempo de passagem que o crepúsculo sugere é antes o estado da cidade que um processo. Essa escolha dá à urbe de Borges um aspecto irreal, mas cuja artificiosidade supera em muito a artificialidade; como define Enrique Pezzoni, o entardecer de Fervor de Buenos Aires é "(...) la lenta e indefinida frontera entre el día y la noche", quando "El caminante deambula por las calles-santuario (...), prolongando el compromiso entre lo real y lo simbólico" (Pezzont, 1986, p.83) ${ }^{25}$. Nesse sentido, a realidade passa por um tratamento poético que amarela as suas cores, dando-lhe o aspecto granular de um tempo aprisionado em uma amada fotografia - o tempo de um afeto ${ }^{26}$. Pois, como consta em "Un patio", "Esa noche, la luna, el claro círculo, / no domina el espacio" (BORGES, 1994, p. 23, v. 3-4)27: a noite por vir não advém, mas permanece anunciada no melancólico instante de um fim que ainda não ocorreu.

Essa espécie de tratamento que a poética borgeana dá a Buenos Aires apaga o objeto real ao escrever sobre ele uma cidade que jamais existira, a não ser como criação ${ }^{28}$. "Calle desconocida" figura essa tensão, mas o faz de forma sutil: a "tarde de plata" em que se encontra o enunciador dá "su ternura a la calle" (v. 19-20); ao mesmo tempo, o sujeito poético se dá conta de que as casas são alheias a essa tarde (v. 23-24), que em cada casa uma vida ilumina, com a sua candeia crepuscular, uma visão singular daquela rua, compondo o cortejo imóvel dos que resistem, cada uma a seu modo, à chegada da noite. O sujeito poético, no entanto, não recua em seu propósito, imprimindo sobre o poema a meia luz de seu dia, oferecendo sua iluminação à montagem poética. Assim segue o livro, à procura da tarde que ao mero descuido se esfacelará. Eis a ameaça em torno da qual se equilibra o poema "Amanecer":

[25] “(...) a lenta e indefinida fronteira entre o dia e a noite”; "O caminhante perambula pelas ruas-santuário (...), prolongando o compromisso entre o real e o simbólico".

[26] Como belamente nota Roland Barthes, no seminal A câmara clara: “O nome da Fotografia será então: 'Isso-foi', ou ainda: o Intratável (...): isso que vejo encontrou-se lá, nesse lugar que se estende entre o infinito e o sujeito (operador ou spectator); ele esteve lá, e todavia de súbito foi separado; ele esteve absolutamente, irrecusavelmente presente, e no entanto já diferido" (2012, p.72-73).

[27] "Nesta noite, a lua, o claro círculo, / não domina seu espaço." (Borges, 2000, p.33).

[28] Deixo ressoar, aqui, o que com Lacan podemos chamar de tempo da rasura, operação que guarda relações com a sublimação: "(...) é pela conjunção [do traço primário e daquilo que o apaga] que ele se faz sujeito, mas por aí se marcarem dois tempos. É preciso, pois, que se distinga nisso a rasura. Rasura de traço algum que Ihe seja anterior (...)" (2003, p. 21). 


\author{
(...) \\ ¡Hora en que el sueño pertinaz de la vida \\ corre peligro de quebranto \\ hora en que le sería fácil a Dios \\ matar del todo Su obra! \\ Pero de nuevo el mundo se ha salvado. \\ La luz discurre inventando sucios colores \\ y con algún remordimiento \\ de mi complicidad en el resurgimiento del día \\ solicito mi casa, \\ atónita y glacial en la luz blanca, \\ mientras un pájaro detiene mi silencio \\ y la noche gastada \\ se ha quedado en los ojos de los ciegos. \\ (Borges, 1994, p. 38-39, v. 38-50) ${ }^{29}$.
}

O poema traz, quiçá, um dos momentos de maior tensão de Fervor de Buenos Aires. Em "Amanecer”, a transição entre os ciclos temporais emerge como ameaçador: o irromper de um novo dia anuncia a possibilidade de mudança, que, para o sujeito poético, periga pôr fim a seu enternecido projeto. A alteração da "honda noche universal" (BORGES, 1994, p. 38, v.1) para o "resurgimiento del día" (p. 39, v.55) ${ }^{30}$ é marcada por uma quebra entre a primeira e a segunda estrofe, sugerindo, a partir de uma hesitação formal, que a iminência do novo é a mola mestra de um arriscado jogo de perdas. Ao fim do poema, a noite (agora gasta e recoberta pelo dia) permanece apenas nos olhos dos cegos - dramático como a vã imagem que a retina não forma, mas que se anima ao risco do gesto poético.

O perigo da mudança demarca com regularidade os pontos de tensão em Fervor de Buenos Aires: o “(...) presentimiento tembloroso / del amanecer horrible que ronda / los arrabales desmantelados del mundo" de "Amanecer" (p. 38, v. 5-7), “(...) aquel brillo desesperado y final” de "Afterglow" (p. 37, v.4), ou ainda "El poniente que no se cicatriza" de

[29] "(...) Hora em que o sonho contumaz da vida / corre o risco de quebranto, / hora em que para Deus seria fácil / matar inteiramente Sua obra! // Mas o mundo salvou-se novamente. / A luz se estende e inventa cores sujas / e com um certo remorso / de minha cumplicidade no ressurgir do dia / solicito minha casa, / atônita e glacial na luz branca, / enquanto um pássaro detém o silêncio / e a noite gasta / permaneceu nos olhos dos cegos." (BORGES, 2000, p. 65)

[30] “(...) profunda noite universal”; “(...) ressurgir do dia” (BoRGEs, 2000, p.65) 
"Campos atardecidos" (p.49, v.10) 31, indicam que a tensão entre a cidade real e a figuração poética, embora não pronunciada, está em operação: a cidade de Borges é estática, mas não imutável, exigindo do sujeito poético uma cuidadosa manutenção para sustentar esse frágil “(...) si-

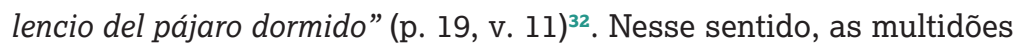
são abafadas, e o seu rumor é transfigurado no plácido cenário em que subsiste o entardecer borgeano:

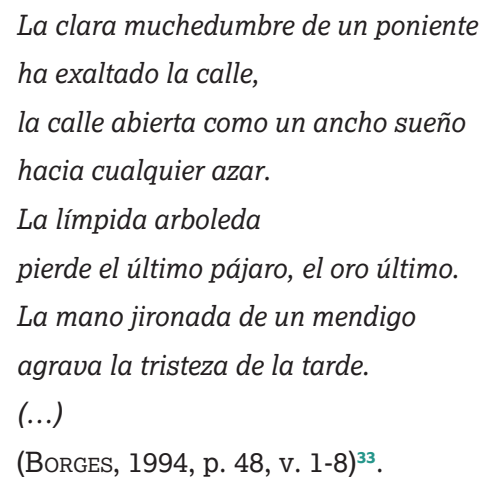

Em "Atardeceres", a multidão aparece atrelada ao tempo crepuscular: ela compõe a rua aberta como um vasto sonho; a mão do mendigo integra-se à contemplação da tarde, agravando sua tristeza. Assim como qualquer outro elemento urbano - seu ritmo acelerado, seus burburinhos, seus acidentes, as mudanças físicas e sociais - o povo serve para pintar uma imagem, congelar o tempo, referir à tarde, e não o contrário. A massa de uma Buenos Aires que muda e se moderniza está antes submetida a um projeto que busca uma cidade "No sólo (...) anacrónica (...), sino que (...) ahistorica", pelo qual "Buenos Aires se proyecta en la eternidad" (LEFERE, 2009, p.151) 34: as pessoas, na ausência do tempo, são tão estáticas

[31] “(...) trêmulo pressentimento / do amanhecer terrível que ronda / os arrebaldes devastados do mundo." (p.65); "(...) o fulgor desesperado e final” (p.61); "O poente que não cicatriza" (p.91).

[32] “(...) silêncio do pássaro que dorme" (p.23)

[33] "A clara profusão de um poente / enalteceu a rua, / a rua aberta como um vasto sonho / para qualquer acaso. / O límpido arvoredo / perde o último pássaro, o ouro último. / A mão andrajosa de um mendigo / agrava a tristeza dessa tarde. / (...)" (p.89).

[34] "Não só anacrônica (...), mas ahistórica"; "Buenos Aires se projeta na eternidade". 
quanto as ruas (BoRGES, 1994, p. 17, v. 16-17) - ruas que "Son para el solitario una promesa" (p.17, v.15) $)^{35} 36$.

\section{IV. À GUISA DE CONCLUSÃO: ENTRE DOIS TEMPOS, ENTRE DUAS CIDADES.}

Em um gesto de maestria, a ser futuramente consolidado pelo grande Borges, um jovem poeta argentino funda um espaço urbano que se desembaraça dos problemas colocados pela modernidade literária: enquanto em Baudelaire as tensões são levadas ao limite, figurando no primeiro plano de seu fazer poético, Borges as silencia através de um ousado gesto autoral - que ironicamente, assim como ocorre com Baudelaire, fora duramente criticado em sua época (cf. CAJERO, 2006, p.113). A tentativa de alocar os dois escritores, então, na cronologia de uma tradição fundada em torno da experiência urbana não poderia resultar mais capciosa: pois, imune ao tempo e seus efeitos, a Buenos Aires de Borges arrisca a cada momento deixar irromper as tensões com as quais Baudelaire se debatera, trazendo, em negativo, um diálogo tão irreal quanto a mítica urbe cantada em Fervor de Buenos Aires. Talvez seja exatamente por isso que esta relação pôde ser traçada: como criação, reinscrição, rasura ${ }^{37}$.

A flânerie povoada de Baudelaire, que “(...) amava a solidão, mas a queria na multidão" (BENJAmin, 1989, p. 47), de alguma forma ecoa na solitária dicção borgeana, que esvazia a sua cidade para, a passos milimetricamente elaborados, inscrever uma experiência que não se funda pelo "fervor agressivo" do poeta moderno; pelo contrário, o fervor borgeano, parece, faz jus a uma segunda acepção: “"celo ardiente y afectuoso hacia las cosas de piedad y religión'. Fervor casi religioso, en verdad" (Pezzoni, 1986, p.67) ${ }^{38}$. Nesse fervor, que não visa a realidade, mas o que

[35] "São para o solitário uma promessa" (BoRgES, 2000, p.17).

[36] Como traz Robin Lefere: “(...) un personaje, que supuestamente se corresponde con Borges, encarna la voz lírica y da cuerpo a la visión, al mismo tiempo que nos presenta un espacio mediatizado y vivido por el. (...) A medida que estos [lugares elegidos o inventados] se van experimentando, presenciamos el marco dramático de una ciudad vaciada de sus habitantes.” ["(...) um personagem, que supostamente corresponde a Borges, encarna a voz lírica e dá corpo à visão ao mesmo tempo em que nos apresenta um espaço mediado e vivido por ele. (...) À medida que estes \{lugares eleitos ou inventados\} vão sendo experimentados, presenciamos o marco dramático de uma cidade esvaziada de seus habitantes."] (LeFERE, 2009, p. 155).

[37] Como traz Sylvia Molloy: “(...) el recuerdo de Baudelaire persiste incómodamente en la obra de Borges, sous rature” [“(...) a recordação de Baudelaire persiste incomodamente na obra de Borges, sous rature [sob rasura]”] (1999, p.192).

[38] "'zelo ardente e afetuoso às coisas de piedade e religião'. Fervor quase religioso, na verdade". 
a poesia pode fazer dela, a desintegração da aura posta em processo por Baudelaire (cf. Benjamin, 1989, p.145) encontra, com Borges, um artificioso reestabelecimento - ali onde a escrita acolhe, contemplativa, a realização do ato poético. Não há choque em Fervor de Buenos Aires, apenas o tempo suspenso na mão do poeta que, acrônico, revisita uma cidade que nunca existira. I

PATRÍCIA LEME - Doutoranda em Teoria Literária e Literatura Comparada pela Faculdade de Filosofia, Letras e Ciências Humanas - FFLCH/USP. São Paulo-SP, Brasil. patricia.oleme@gmail.com. Esse artigo foi produzido para a conclusão do curso "Escrita do Eu, Memória, Natureza e Experiência Urbana”, ministrado pela profa. Dra. Marta Kawano no primeiro semestre de 2015. 


\section{REFERÊNCIAS BIBLIOGRÁFICAS}

AGAMBEN, Giorgio. Estâncias. Belo Horizonte: Editora UFMG, 2007.

“O que é o contemporâneo?”. In: O que é o contemporâneo? e outros ensaios. Chapecó: Argos, 2009, pp.55-73.

AUERBACH, Eric. "As flores do mal e o sublime". In: Ensaios de literatura ocidental. São Paulo: Editora 34, 2007, pp.303-332.

BARTHES, Roland. A câmara clara. Rio de Janeiro: Nova Fronteira, 2012.

BAUDELAIRE, Charles. As flores do mal: edição bilingüe (Ivan Junqueira trad.). Rio de Janeiro: Nova Fronteira, 2006

Pequenos poemas em prosa: edição bilingüe (Gilson Maurity Santos tad.). Rio de Janeiro: Editora Record, 2006.

BENJAMIN, Walter. Charles Baudelaire: um lírico no auge do capitalismo. São Paulo: Editora Brasiliense, 1989.

BORGES, Jorge Luis. Fervor de Buenos Aires. In: Obras Completas, tomo 1. Buenos Aires: Emecé Editores, 1994.

. “La muerte y la brújula”. In: Antología personal. Buenos Aires: La Biblioteca Argentina, 1996, pp.7-16.

"Borges y yo". In: Ficcionario - una antología de sus textos.

(Emir Rodrígues Monegal org.). México: Fondo de Cultura Económica, 1997, p.351.

. Fervor de Buenos Aires. In: Obras Completas, volume 1. São Paulo: Globo, 2000.

. Primeira poesia. (Josely V. Baptista trad.). São Paulo: Companhia das Letras, 2007.

"Borges e Eu". In: . O fazedor. (Josely Vianna Baptista trad.).

São Paulo: Companhia das letras, 2008. 
CAJERO, Antonio. "A quien leyere”: La poética de Fervor de Buenos Aires. Variaciones Borges 22, nov. 2006, pp.101-128.

(http://www.borges.pitt.edu/bsol/documents/2206.pdf, acesso em 03/07/2015)

FREUD, Sigmund. "Duelo y melancolía” (1915). In: Obras Completas. Buenos Aires: Amorrortu editores, 1991, vol. 14, pp.241-256. "Más allá del principio de placer» (1920). In: Obras completas. Buenos Aires: Amorrortu editores, 1989, vol.18, pp.7-62. “Nota sobre la 'pizarra mágica”” (1925). In: Obras Completas. Buenos Aires: Amorrortu editores, 1992, vol.19, pp.243-247.

FRIEDRICH, Hugo. Estrutura da lírica moderna. São Paulo: Duas Cidades, 1978.

JOZEF, Bella. "J. L. Borges, o último criador de mitos”. In: CID, Marcelo; MONTOTO, Cláudio César (orgs.). Borges centenário. São Paulo: Educ, pp.29-38. LACAN, Jacques. "Lituraterra". In: . Outros escritos. (Vera Ribeiro trad.) Rio de Janeiro: Jorge Zahar Ed., 2003, pp.15-25.

LEFERE, Robin. "De los procesos semánticos creadores de ciudades (literarias): el caso de Fervor de Buenos Aires". In: MONTENI, Maria Luisa; SCARABELLI, Laura (eds.) Los ojos en la ciudad. Milão: Arcipelago Edizioni, 2009, pp.149-158.

MOLLOY, Sylvia. "Flâneries textuales: Borges, Benjamin y Baudelaire”. In: . Las letras de Borges y otros ensayos. Rosario: Beatriz Viterbo Editores, 1999, pp.191-207.

PEZZONI, Enrique. "Fervor de Buenos Aires: autobiografía y autorretrato". In: __ El texto y sus voces. Buenos Aires: Editorial Sudamericana, 1986, pp.67-96.

PIGLIA, Ricardo. Formas breves. São Paulo: Companhia das Letras, 2004.

SARLO, Beatriz. Jorge Luis Borges, um escritor na periferia. São Paulo: lluminuras, 2008. 
STAROBINSKI, Jean. A melancolia diante do espelho - três leituras de

Baudelaire. São Paulo: Editora 34, 2014.

STIERLE, Karlheinz. «Le groupe des 'Tableaux parisiens'». In: La capitale des signes: Paris et son discours. Paris: Éditions de la Maison des sciences de l'homme, 2001, pp.451-543.

TROCOLI, Flávia. "Proust em dois tempos: a não resposta e as rasura”. In: LEITE, Nina V. de Araújo; MILÁN-RAMOS; SALZANO, Maria Rita (orgs.). De um discurso sem palavras. Campinas: Mercado de Letras, 2012, pp.205-216.

VALÉRY, Paul. "Situação de Baudelaire”. In: Variedades. São Paulo:

lluminuras, 2011, pp.19-29. 
